\title{
Alinhamento estratégico de gestores pela atribuição de pesos para indicadores de desempenho: evidência empírica de um hospital público brasileiro
}

\section{Henrique Portulhak, Márcia Maria dos Santos Bortolocci Espejo}

Universidade Federal do Paraná Departamento de Contabilidade

A investigação buscou verificar empiricamente se ocorrem diferenças na importância atribuída a indicadores estratégicos de avaliação de desempenho por gestores de diferentes níveis hierárquicos de uma organização. Procedeu-se um estudo de caso em um hospital universitário federal localizado na região Sul do Brasil, no qual foi realizada uma modelagem de um sistema estratégico de avaliação de desempenho com base no modelo Public Value Scorecard, por sua vez utilizado para cascateamento e atribuição de pesos aos indicadores elaborados e destinados a 31 gestores da organizaçáo investigada. Com base em técnicas de estatística descritiva, a pesquisa apresentou indicaçôes a respeito das diferenças entre os pesos atribuídos aos indicadores de desempenho, bem como sobre os comportamentos de dispersão na atribuição de pesos, tanto de acordo com o nível hierárquico quanto para cada perspectiva do modelo Public Value Scorecard.

Palavras-chave: indicadores de desempenho, avaliação de desempenho, alinhamento estratégico, Public Value Scorecard.

\section{Managerial Strategic Alignment by Weighting Performance Indicators: Empirical Evidence of a Brazilian Public Hospital}

The study aimed to verify, empirically, if there are differences in the importance of strategic performance indicators assigned by managers at different hierarchical levels of an organization. A case study was carried out at a national teaching hospital, located in the South Region of Brazil, using a strategic performance evaluation system based on the Public Value Scorecard model, and, in turn, used for cascading and weight values assigned by 31 managers working in this organization. Based on descriptive statistics, this research showed the difference in weightage of performance indicators, and distribution patterns according to the hierarchical level and the perspective of the Public Value Scorecard model.

Keywords: Performance indicators, performance evaluation, strategic alignment, Public Value Scorecard.

\section{Alineación estratégica de gestión según la ponderación de indicadores de desempeño: evidencia empí- rica de un hospital público en Brasil}

El estudio tuvo como objetivo verificar empíricamente si los gerentes de diferentes niveles jerárquicos de una organización le otorgan a los indicadores estratégicos de desempeño distintos niveles de importancia. El estudio se realizó en un hospital universitario estatal ubicado en la región sur de Brasil; ahí se elaboró un modelo de evaluación del desempeńo basado en el Public Value Scorecard, y este a su vez se utilizó para el efecto en cascada y para que 31 directivos de la organización investigada asignen valores a estos indicadores. Según estadísticas descriptivas, la investigación muestra las diferencias en los valores asignados a los indicadores de desempeńo, tanto en el comportamiento de distribución de ponderación, como en el nivel jerárquico, según la perspectiva de cada modelo Public Value Scorecard.

Palabras clave: indicadores de desempeño, evaluación del desempeño, alineación estratégica, Public Value Scorecard. 


\section{Introdução}

O alinhamento das atividades realizadas pelas diversas unidades de uma organização é uma característica capaz de gerar sinergias que trazem à instituição fontes adicionais de geração de valor e melhoria de desempenho, especialmente pela possibilidade de aumentar a efetividade da implantação da estratégia, melhorar o nível das atividades realizadas pelos empregados e pela promoção de integração dos sistemas de gestão (Powell, 1992; Kaplan \& Norton, 2006).

Nesse sentido, os sistemas de avaliação de desempenho podem beneficiar as organizaçóes ao promoverem maior alinhamento entre aperfeiçoamentos operacionais e estratégia organizacional (Elzinga, Albronda \& Kluijtmans, 2009), sendo o alinhamento estratégico uma de suas importantes funçóes (Bortoluzzi, Ensslin, Ensslin \& Vicente, 2010) e, ao mesmo tempo, um importante fator para seu sucesso (Franco-Santos \& Bourne, 2005). Em consequência, o alinhamento promovido pelos sistemas de avaliação de desempenho é encarado como uma característica que motiva a sua adoção pelas empresas (Kaplan \& Norton, 1996).

Tendo em vista os benefícios que o alinhamento estratégico pode oferecer às organizaçóes, e o papel dos sistemas de avaliação de desempenho para a promoção desse alinhamento, é salutar que tais sistemas estejam integrados à estratégia da organização para que sejam capazes de exercer essa função. Para tal, a formulação de sistemas estratégicos de avaliação de desempenho envolve a formação de indicadores de desempenho financeiros e não financeiros com foco explícito na estratégia definida pela organização (Chenhall \& Langfield-Smith, 1998; Kaplan, 2009). Em consequência, tais indicadores são geralmente acompanhados por metas de desempenho, que possuem como função direcionar os esforços dos colaboradores da organização de acordo com os interesses declarados na estratégia definida, e que podem contar com planos de recompensa atrelados ao seu alcance, buscando motivar os gestores a empreender esforços de acordo com a estratégia definida corporativamente (Chenhall \& Langfield-Smith, 2003; Veen-Dirks, 2010).

Ao serem atribuídas metas derivadas dos indicadores de desempenho, pode-se esperar que, de um determinado rol de metas atribuídas a um determinado gestor, esse possa elencar suas prioridades de acordo com interesses individuais, caso esse não possua uma instrução pré-determinada a respeito dos itens prioritários para a organização em geral. Dessa forma, como entendem DeBusk, Brown e Killough (2003) e Ittner, Larcker e Meyer (2003), os pesos possuem papel na promoção da congruência de prioridades entre os gestores da organização, sendo os pesos para as medidas de desempenho expressões que refletem a importância de cada fator - indicadores e metas - para a organização em geral. Portanto, faz-se importante sua atribuição para cada medida de desempenho para que ocorra um adequado alinhamento das prioridades individuais e setoriais com as prioridades organizacionais (Malina \& Selto, 2001; Ittner et al., 2003).

Por outro lado, pode-se entender que, se não há alinhamento da importância atribuída aos diferentes indicadores e metas existentes em um sistema de avaliação de desempenho (função exercida pelos pesos), tal fator pode comprometer a efetividade do sistema de avaliação de desempenho (Banker, Potter \& Srinivasan, 2000; Smith, 2002), caso a empresa considere o alinhamento estratégico como uma das principais motivações de sua adoção.

Diante desse raciocínio, faz-se necessário a apresentação de evidências empíricas que indiquem a ocorrên- 
cia - ou não - de discrepância no estabelecimento de prioridades entre diversos níveis hierárquicos de uma organização para um determinado rol de medidas de desempenhos derivadas da estratégia da organização, prioridades essas que podem ser observadas na atribuição de pesos para os indicadores de desempenho, já que muitas das afirmaçóes existentes a respeito na literatura acadêmica possuem como base pressupostos teóricos (ex. Bergeron, Raymond \& Rivard, 2004; Chenhall, 2005; Bush, Lederer, Li, Palmisano \& Rao, 2009). Com isso, a presente investigação busca responder a seguinte questão: gestores de diferentes níveis hierárquicos de uma organização atribuem pesos diferentes para indicadores de desempenho organizacional, evidenciando a ausência de alinhamento estratégico de prioridades?

A investigação em tela, portanto, teve como principal objetivo verificar empiricamente se ocorrem diferenças na importância atribuída a indicadores estratégicos de avaliação de desempenho por gestores de diferentes níveis hierárquicos de uma organização. Além disso, a pesquisa busca apresentar verificar, caso haja a ocorrência de diferenças, a amplitude de tais discrepâncias, ou seja, se a distância na estrutura hierárquica acentua as diferenças na importância atribuída para indicadores de desempenho.

A relevância da investigaçáo realizada é ressaltada ao considerar que discussóes acerca da atribuição de pesos em sistemas estratégicos de avaliação de desempenho são importantes por essa ser considerada uma tarefa complexa, dispendiosa com relação a tempo, e que pode gerar diversos conflitos entre gestores na busca de consensos a respeito da adequabilidade de cada peso (Herath, Bremser \& Birnberg, 2010; Boulianne, 2012).
Da mesma forma, estudos dessa natureza podem agregar informaçóes úteis para aqueles envolvidos no desenvolvimento de sistemas estratégicos de avaliaçáo de desempenho, tendo em vista que o processo de desenvolvimento e implantação de um sistema com tal característica é geralmente custoso (Lipe \& Salterio, 2000). Quanto às justificativas teóricas, ressalta-se principalmente a necessidade de realização de estudos com tal temática, já que, conforme Herath et al. (2010), existem poucas investigações empíricas que tratam da questáo da atribuição de pesos a medidas de indicadores estratégicos de avaliação de desempenho.

\section{Plataforma teórica}

\subsection{O alinhamento estratégico e a atribuiçáo de pesos para indicadores}

Dentre as ações necessárias para que uma organização seja capaz de colocar a estratégia como o centro de seu processo de gestão, Kaplan e Norton (2001) evocam: (i) traduzir a estratégia em termos operacionais, (ii) alinhar a organização para a estratégia, (iii) fazer da estratégia o trabalho do dia-a-dia de cada colaborador, (iv) fazer da estratégia um processo contínuo de construção e (v) mobilizar o processo de mudança por meio da liderança executiva.

Nota-se que, de acordo com Kaplan e Norton (2001), o alinhamento é considerado um fator importante para que a estratégia de uma empresa tenha maiores condiçóes de ser alcançada. Tal posicionamento também pode ser notado em outras obras. Bart e Tabone (1998), tomando como base a literatura acadêmica, ressalta que o sucesso na implementação da estratégia de negócios pode depender de seu alinhamento com os principais processos e sistemas da organização. Já Chenhall (2005), levando em consideração evidências 
empíricas, apresenta o alinhamento estratégico como um elemento capaz de gerar vantagens competitivas para a organização. Em especial, o Balanced Scorecard (BSC), sistema estratégico de avaliação de desempenho, é defendido como um artefato capaz de ajudar a organização a alinhar a estratégia organizacional com as iniciativas individuais e interdepartamentais (Galas \& Ponte, 2006; Kaplan \& Norton, 2006).

De acordo com Bergeron et al. (2004), o alinhamento estratégico tem sua proposição fundamentada no argumento de que o desempenho organizacional é consequência do ajustamento entre diversos fatores como estratégia, estrutura, tecnologia, cultura e ambiente. Como afirmam os autores, as empresas que possuem adequado alinhamento entre estratégia e sua estrutura tendem a diminuir sua vulnerabilidade a mudanças no ambiente externo e a ineficiências que possam ocorrer internamente, e dessa forma, possam ter um desempenho melhor.

Da mesma forma, Chenhall (2005) considera o alinhamento estratégico importante por ser uma ferramenta que assegura que a estratégia definida pela organização seja comunicada ao nível de processo, fornecendo a oportunidade de desenvolvimento de produtos e processos de acordo com as prioridades organizacionais. Chenhall (2005) também ressalta que, com um adequado alinhamento estratégico, as decisóes dos gestores podem ser avaliadas de acordo com sua coerência aos principais objetivos da organização.

Corroborando ao exposto, Bush et al. (2009) afirmam que o principal argumento que baseia a importância do alinhamento nas organizaçóes é que, com sua adequada ocorrência entre as áreas da organização, as açóes empreendidas em qualquer área funcional podem viabilizar o alcance dos objetivos definidos como críticos pela alta administração e, por outro lado, a ausência de alinhamento estratégico pode provocar a perda de oportunidades de melhoria e desperdício de recursos.

Em específico, Franco-Santos, Lucianetti e Bourne (2012) consideram que o alinhamento estratégico é uma característica importante a ser considerada nas organizaçóes que buscam alcançar vantagens competitivas, sendo algo esperado quando a organização decide por utilizar um sistema estratégico de avaliação de desempenho. Tomando como base teorias da comunicação e da informação, é possível predizer que sistemas estratégicos de avaliação de desempenho podem ajudar no desenvolvimento do alinhamento entre estratégia e operaçóes (Chenhall, 2005). O alinhamento entre estratégias de negócios e sistemas de informação é considerado um fator preponderante para uma empresa que busca ser competitiva, influenciando positivamente na efetividade dos sistemas de informação e no desempenho organizacional, sendo esse fator uma das principais preocupaçóes de executivos (Avison, Jones, Powell \& Wilson, 2004; Dong, Liu \& Yin, 2008).

Vale notar que a preocupação exposta ocorre de forma recíproca, pois o alinhamento do sistema de avaliação de desempenho, o que envolve a congruência de prioridades de gestores e suas áreas de responsabilidade, também é encarado como um fator importante para a implantação e para o uso satisfatório desse artefato (Waal, 2003). Como exemplo, Assiri, Zairi e Eid (2006) verificaram empiricamente, sob o ponto de vista de gestores de empresas de 25 países, que o alinhamento corporativo é considerado um dos principais fatores para o sucesso da implantação de um sistema estratégico de avaliação de desempenho como o BSC.

Kaplan e Norton (2006) explicam que grandes empresas são divididas em diversas unidades, e que nessas 
organizaçóes há um grande desafio em coordenar as atividades realizadas por essas unidades para que essas possam trabalhar em prol de benefícios a serem gerados para a organização em geral, já que frequentemente a falta de sincronização de iniciativas e atividades pode gerar esforços em direçáo distinta ao desejado. Nesse sentido, os autores defendem que sistemas estratégicos de avaliaçáo de desempenho - como o BSC - podem ajudar a empresa a alinhar as atividades realizadas pelas unidades de negócios com a estratégia corporativa.

Mesmo assim, é importante observar que na implantação de um sistema estratégico de avaliação de desempenho podem ocorrer conflitos entre a alta administraçáo e gestores alocados em níveis hierárquicos mais baixos, especialmente na definição das prioridades dentre um conjunto de indicadores definidos (Herath et al., 2010). Dessa forma, acredita-se que o alinhamento das prioridades estratégicas entre alta administração e gestores subordinados será efetivo quando o sistema for capaz de contribuir para a melhoria do desempenho organizacional ao mitigar os efeitos de tais conflitos (Joshi, Kathuria \& Porth, 2003).

Outro fator considerado importante para o sucesso de um sistema estratégico de avaliação de desempenho é a vinculação de recompensas com o alcance de metas definidas com base nos indicadores de desempenho formulados por meio desse artefato (Kaplan \& Norton, 1996). Entretanto, quando há o envolvimento de recompensas atreladas a medidas de desempenho, os empregados podem promover iniciativas em suas atividades que tenham como principal enfoque o aumento de suas compensações, afetando dessa forma suas decisóes sobre quais devem ser as açóes consideradas prioritárias (Baker, Gibbons \& Murphy, 1994).

Diante de tal contexto, entra em questáo o papel dos pesos. Os pesos possuem o papel de demonstrar para

os gestores da organizaçáo que possuem metas a cumprir sobre quais as iniciativas que devem ser priorizadas dentre um conjunto de indicadores presentes em um sistema estratégico de avaliaçáa de desempenho (Herath et al., 2010).

De acordo com Kelly (2010), os pesos atribuídos às medidas de desempenho buscam representar a prioridade de cada ação para o alcance dos objetivos organizacionais. A autora considera que, por conta da existência de múltiplas medidas de desempenho, a adequada atribuição de pesos às medidas é um fator crítico para que os gestores possam decisôes mais acuradas a respeito de alocação de recursos limitados para açôes que possam maximizar o valor da empresa. Com o mesmo raciocínio, Ittner e Larcker (2003) consideram que não atribuir pesos para as medidas de desempenho pode dificultar a tarefa de alocaçáo de recursos de forma adequada com vistas ao alcance da estratégia definida.

A forma como são atribuídos os pesos aos indicadores de desempenho, especialmente quando o alcance das metas relacionadas está atrelado a um plano de recompensas, possui influência na motivação dos gestores quanto à intensidade e à alocação de suas ações (Datar, Kulp \& Lambert, 2001).

O comportamento dos gestores é influenciado pelos pesos atribuídos às medidas de desempenho, e uma distribuição inadequada dos pesos pode resultar em uma alocação subótima dos esforços desses gestores (Smith, 2002), especialmente quando há a possibilidade de influenciar no processo de definiçáo dos pesos, atribuindo mais importância para metas nas quais se esperam maior possibilidade de alcance, visando facilitar o alcance de recompensas (Banker et al., 2000). Ittner e Larcker (2003) corroboram essa percepção, ao afirmarem que, por vezes, um processo inadequado de 
definição de pesos pode dar margem a ineficiências promovidas por gestores, como buscar fazer valer suas opinióes individuais na importância das medidas de desempenho, ou ainda buscar atribuir maior peso a medidas ligadas a metas que acreditam ter maior possibilidade de alcançar.

Nesse contexto, vale ressaltar a investigação realizada por Boulianne (2012), que buscou verificar o efeito da atribuição de pesos às perspectivas de três sistemas de avaliação de desempenho baseados no modelo BSC: o primeiro contou com as quatro perspectivas com pesos atribuídos pelos gestores, o segundo teve os pesos atribuídos igualmente entre as perspectivas, e o terceiro com peso atribuído apenas para a dimensão financeira. A autora ressalta que a atribuição de diferentes pesos reflete as prioridades específicas do negócio, e comenta que, enquanto alguns relatos acadêmicos apresentam benefícios relacionados a essa prática, outros relatos reportam inconvenientes como o incentivo de favoritismos ou até mesmo a ausência de efeitos significantes pela sua utilização.

Boulianne (2012) elenca diversos pontos de vista acerca da atribuição de pesos no processo de elaboração do sistema de avaliação de desempenho. Inicialmente, apresenta-se como um potencial benefício sua utilização no processo de avaliação do desempenho da cada unidade de negócio e para oferecer ênfase a determinados objetivos apresentados aos gestores. Por outro lado, o artigo menciona potenciais pontos negativos na atribuiçáo de pesos a indicadores, especialmente por tratar-se de um processo envolto em subjetivismo. De acordo com a autora, a atribuição subjetiva de pesos pode conduzir gestores a ignorar indicadores importantes que possuam pesos menores que outros, além de tal processo possibilitar o reflexo de preferências individuais dos gestores envolvidos nesse processo.

\subsection{O alinhamento estratégico e a atribuição de pesos para indicadores em organizaçóes públicas e hospitalares}

Kaplan (2001) considera que avaliação de desempenho em entidades sem finalidades lucrativas é uma questáo urgente e que precisa ser abordada especialmente pela necessidade de se colocar o objetivo da existência dessas organizações e a avaliação da efetividade de suas açóes como foco principal, possibilitando melhorias no desempenho quanto à captação de recursos, restrição relevante para a atividade dessas organizações. Sobre as organizaçóes sem fins lucrativos - onde se incluem as organizaçóes públicas - o mesmo autor considera que, para a avaliação de desempenho, deve ser considerado como principal enfoque de resultados a missão social da entidade - a razão de sua existência - e, em consequência, os objetivos inseridos no sistema de avaliação de desempenho devem possibilitar o alcance da missão social declarada.

Nesse sentido, o alinhamento estratégico também é uma questão importante para a melhoria do desempenho dessas organizaçóes. Kaplan (2001) afirma que o alcance de alinhamento estratégico é particularmente difícil para entidades sem finalidades lucrativas, tomando como base o pressuposto de que, nessas organizaçóes, os valores e anseios das pessoas que fazem parte da instituição podem ser uma força relevante na definição de atividades e iniciativas das unidades, que por sua vez podem acompanhar ou não os objetivos organizacionais.

Nota-se no Brasil algumas iniciativas de realização de avaliação de desempenho em organizações públicas, considerando não apenas a importância do alinhamento estratégico, mas também a utilização de pesos para prover maior probabilidade de efetivaçáo desse alinhamento. Como exemplo, a Agência Nacional 
de Energia Elétrica (ANEEL) declara atribuir pesos para as dimensóes e para os indicadores institucionais, partindo do pressuposto de que as açóes e programas refletidos em seu sistema de avaliação de desempenho possuem diferentes graus de complexidade, importância e dificuldade, o que justifica a adoção de uma escala de pesos que reflita tais aspectos (Debus, 2012). Já a Agência Nacional de Saúde Suplementar (ANS) utiliza pesos para os indicadores de avaliaçáo de desempenho das operadoras de saúde suplementar, que por sua vez são utilizados para compor a nota de cada dimensáo que representa a adequação das empresas que atuam nesse setor (ANS, 2014).

Também é importante nesse contexto ressaltar a proposta realizada pelo Programa Nacional de Gestão Pública e Desburocratização (GESPÚBLICA) para a medição do desempenho e construção de indicadores para os órgãos componentes da administração pública brasileira. De acordo com o guia, a atribuição de diferentes pesos para os indicadores de desempenho pode ser um meio capaz de representar as distintas importâncias de cada aspecto avaliado (GESPÚBLICA, 2009).

Tratando em específico de organizaçóes que estão envolvidas em atividades de atenção à saúde, Bart e Tabone (1998) afirmam que a escassez de recursos e a influência exercida pelo ambiente externo tornam a declaração de missão e estratégia uma ferramenta particularmente importante para hospitais sem fins lucrativos. De acordo com os autores, uma estratégia bem definida e articulada pode ajudar a instituição a ser mais eficiente e ter mais condiçóes de garantir a continuidade organizacional.

Da mesma forma, Bush et al. (2009) afirmam que o processo de alinhamento de sistemas de informação com os objetivos e estratégias organizacionais é um desafio-chave em particular para as organizaçóes

envolvidas em atenção à saúde. Para os autores, o alinhamento estratégico é um elemento importante para organizaçóes que atuam nessa área, e a contribuição potencial do alinhamento estratégico ao processo de planejamento das organizações tem chamado a atenção e estimulado sua aplicação em entidades atuantes nessa área.

Cita-se como exemplo a investigação realizada por Bart e Tabone (1998) em uma instituição hospitalar sem finalidades lucrativas. Os resultados dessa pesquisa indicaram que há uma relação diretamente proporcional entre o alinhamento organizacional e sua missão e a satisfação dos gestores com a estrutura organizacional. Além disso, os resultados sugerem que o grau de alinhamento estratégico em uma instituição hospitalar sem fins lucrativos possui relação positiva com os resultados apresentados por meio das medidas de desempenho, e quanto maior o alinhamento estratégico, maior a satisfação dos gestores com o desempenho financeiro da entidade. Ainda, Bart e Tabone (1998) indicam a existência de uma pré-disposição dos gestores em fortalecer o alinhamento estratégico para determinados componentes da estrutura da organização em detrimento de outros, enquanto o ideal seria que os mesmos exercessem um papel de modo a garantir que tal alinhamento ocorra adequadamente em todas as dimensôes estruturais.

\section{Metodologia}

Para a realização da pesquisa, procedeu-se um estudo de caso único (Yin, 2001) em uma instituição hospitalar pública localizada na região Sul do Brasil durante o ano de 2013. A realização desse estudo em uma entidade hospitalar pública é relevante devido às características peculiares dessas organizaçóes que trazem complexidade na implantação de sistemas de avaliação de desempenho, como a complexidade dos 
processos, o controle exercido por determinadas classes profissionais e o conflito frequente entre as partes interessadas nas atividades da organização (Abernethy, Chua, Grafton \& Mahama, 2007; Evans, Hwang \& Nagarajan, 2011).

Já a escolha específica da instituição hospitalar se deve ao fato de que, com base em informaçóes iniciais recebidas de seu dirigente máximo, esta não possuía um sistema estratégico de avaliação de desempenho vigente, o que potencialmente proporciona maior validade interna dos resultados da investigação. Outro fator capaz de aumentar a validade interna está relacionado ao perfil dos sujeitos entrevistados (Bryman, 2012) que estão, em média, há três anos no cargo atual e trabalham na instituição há vinte e dois anos, o que pode enquadrar ao caso escolhido como um caso decisivo (Yin, 2001).

Para viabilizar a realização da pesquisa, procedeu-se primeiramente a um processo de modelagem conceitual de um sistema estratégico de avaliação de desempenho, tendo sido escolhido o modelo Public Value Scorecard, artefato baseado no BSC e considerado uma alternativa congruente com as especificidades existentes em organizações sem fins lucrativos (Moore, 2003), e especialmente adequada para organizaçóes públicas hospitalares (Zhang \& Wang, 2010). O referido modelo é composto por três perspectivas: (i) missão social: envolve as questôes-chave que constituem o valor público que busca ser produzido pela entidade; (ii) capacidades operacionais: envolve a produtividade, inovação, capacidade financeira e dos recursos humanos; (iii) legitimidade e apoio: envolve o relacionamento e reputação com financiadores, voluntários, órgãos reguladores, imprensa e população em geral (Moore, 2003).
Com vistas ao alcance dos objetivos da investigação, foram consideradas as sugestôes de Kaplan e Norton (2006) sobre formas de realização de alinhamento organizacional: (i) iniciando pelo ponto hierárquico mais alto e então cascateando para as áreas subordinadas; (ii) iniciando pelas unidades de negócio para na sequência partir para a construção de um mapa estratégico corporativo. Kaplan e Norton (2006) afirmam que, com a utilização de um sistema estratégico de avaliação de desempenho, a apresentação das prioridades corporativas a partir do topo torna-se mais aceitável, e a partir da definição dessas prioridades, sugere-se seu cascateamento ao nível das unidades de negócio. Os mesmos autores, além de Galas e Ponte (2006), argumentam que, para a obtenção de sucesso na utilização de um sistema estratégico de avaliação de desempenho em uma função de promoção de alinhamento organizacional, é salutar o desdobramento desse sistema nos diferentes níveis hierárquicos da organização.

Considerando tais afirmaçóes, procedeu-se a modelagem conceitual do Public Value Scorecard partindo do mais alto nível hierárquico da organização, tomando como base a análise do planejamento estratégico vigente na instituição objeto do estudo e um roteiro de entrevista semiestruturada aplicado junto ao dirigente máximo da organizaçáo. Como resultado, foi elaborado um scorecard composto por 45 indicadores de desempenho, sendo 19 indicadores para a perspectiva "Missão Social», 15 indicadores para a perspectiva «Capacidades Operacionais» e 11 indicadores para a perspectiva "Legitimidade e Apoio», como é apresentado por meio do Apêndice A.

O painel principal retrocitado possui em sua composição, além das perspectivas do modelo Public Value Scorecard, os objetivos estratégicos oriundos do plano estratégico da instituição enquadrados em cada perspectiva do modelo, os indicadores de desempenho 
derivados dos objetivos estratégicos, as metas atreladas aos indicadores de desempenho que devem ser alcançadas para que se atenda ao exposto na estratégia organizacional, os pesos relativos atribuídos a cada um dos indicadores de desempenho pelo dirigente máximo, e as áreas diretamente subordinadas ao dirigente máximo que deveriam empreender açóes para o alcance da meta estabelecida.

Com relação aos pesos, optou-se nessa investigação por aplicar uma escala de intensidade na qual, para cada indicador e meta elaborados, o gestor deveria expressar qual a criticidade do alcance de determinada meta para o alcance dos objetivos apresentados no plano estratégico vigente na instituição. A referida escala foi elaborada e apresentada aos indivíduos entrevistados de forma numérica ao longo da entrevista, sendo uma escala contínua de cinco pontos (1 a 5), onde o número 1 representa menor nível de intensidade ou criticidade, e o número 5 representa maior nível de intensidade ou criticidade.

Já com relação ao cascateamento, esse procedimento tomou como base as informaçóes fornecidas pelo dirigente máximo na entrevista semiestruturada sobre quais áreas diretamente subordinadas deveriam tomar açóes para o alcance de cada meta definida no procedimento descrito nesse tópico, tomando como base de validação a estrutura hierárquica obtida de forma documental da própria instituição. Com a indicação das áreas, esse processo de cascateamento resultou em novos scorecards para cada área subordinada ao dirigente máximo, que por sua vez também atribuíram pesos a cada indicador e indicaram quais áreas subordinadas a elas necessitariam tomar açóes para o alcance da meta atrelada ao indicador. Nesse processo, dois indicadores - um da perspectiva «Legitimidade e Apoio» e um da perspectiva "Capacidades Operacionais» - foram eliminados da investigação por se tratarem de açóes exclusivas do dirigente máximo, não demandando o cascateamento. Dessa forma, 43 indicadores de desempenho foram utilizados para a investigação em tela.

O processo descrito, que teve por objetivo a coleta de dados com relação a pesos atribuídos a indicadores, ocorreu para quatro níveis hierárquicos distintos, de forma sucessiva e de acordo com o organograma da instituição, perfazendo um total de 31 entrevistas de um universo de 34 gestores mapeados, distribuídas da seguinte forma: (i) direção geral (uma); (ii) assessorias (três); (iii) diretorias de área e comissão de licitaçấo (sete) e (iv) unidades funcionais (vinte). Dentre as vinte unidades funcionais, essas podem ser divididas em dois grupos: (a) unidades finalísticas (quatorze): estão ligadas às atividades-fim da organização, como assistência, ensino, pesquisa e extensão; (b) unidades de suporte (seis): estáo ligadas ao processo de fornecimento de condiçôes para a realização das atividades finalísticas da organização. A Figura 1 possibilita visualizar a estrutura hierárquica da organização que serviu como base para a realização da pesquisa.

Figura 1. Estruturra Hierárquica da Organizaçáo Objeto do Estudo

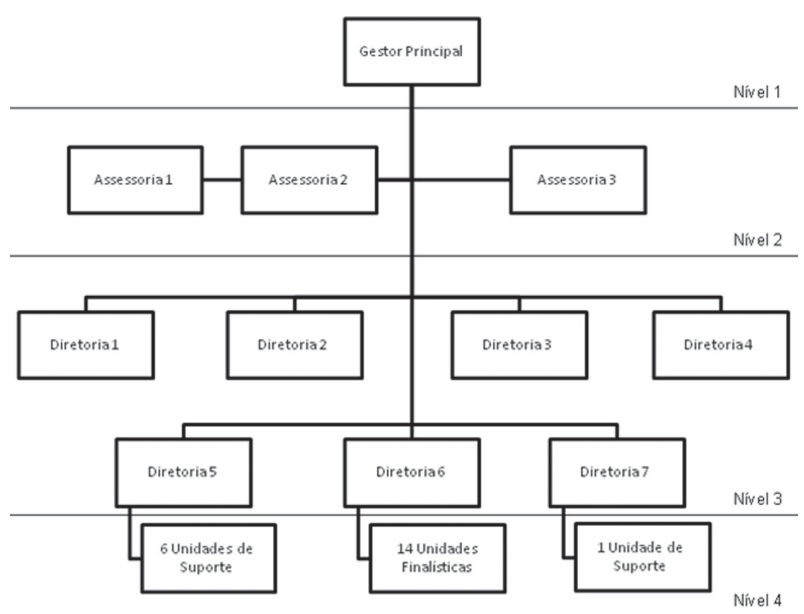

Fonte: Documento interno da instituição 
Vale ressaltar que todo o processo de modelagem conceitual do Public Value Scorecard, que viabilizou a coleta dos dados necessários para a pesquisa foi orientado por um protocolo de estudo de caso elaborado exclusivamente para tal investigação (Yin, 2001), o que envolveu instrumentos de pesquisa como observação participante, análise documental e, aproximadamente, 31 horas de entrevistas realizadas com os gestores tomando como base três roteiros de entrevista semiestruturada compostos por questóes abertas e fechadas e moldados de acordo com o nível hierárquico dos sujeitos (direção geral; diretorias e assessorias; unidades).

Após a coleta dos pesos de acordo com os procedimentos elencados, o que ocorreu entre os meses de abril e setembro de 2013, foram empregados métodos de estatística descritiva para buscar respostas à questão de pesquisa. Para isso, e considerando a realização de um levantamento de dados praticamente censitário (31 entrevistados de uma população de 34 gestores), foram utilizadas técnicas como a verificação de diferença de médias e o coeficiente de variação (Cvar), de forma global, por perspectiva do Public Value Scorecard e por nível hierárquico da organização, tendo como parâmetro de referência as informaçóes obtidas junto ao gestor principal.

\section{Análise de dados}

A Tabela 1 apresenta as informaçóes de caráter geral e detalhado para perspectivas do Public Value Scorecard e diferentes níveis hierárquicos da organização, e que baseiam as inferências elencadas nos itens apresentados na sequência.

\subsection{Comparação entre a percepção do gestor máximo e dos demais gestores}

Em primeiro lugar, buscou-se verificar, de forma geral, se há discrepâncias entre a percepção do gestor máximo da entidade objeto do estudo de caso e a percepção dos demais gestores entrevistados a respeito da hierarquização dos indicadores para a avaliaçáo do desempenho organizacional. Para isso, empreendeu-se uma comparação entre a média dos pesos atribuídos aos indicadores pelos grupos elencados, além de uma análise do coeficiente de variação, visando comparar a dispersão apresentada nos grupos no processo de atribuiçẫo de pesos para os 45 indicadores elaborados.

Como resultado dessa análise (Tabela 1), notou-se que a média dos pesos atribuídos pelo gestor máximo aos indicadores foi de 3,767 , e com relação ao coeficiente de variação notou-se um resultado de 0,172 com relação aos 43 pesos atribuídos. Já com relação ao conjunto de demais gestores, a análise dos pesos atribuídos aos indicadores demonstrou uma média superior dos pesos atribuídos em comparação ao ocorrido com o dirigente máximo $(4,127)$, bem como um coeficiente de variação também superior $(0,236)$. Além do discrepante resultado, em termos gerais, na atribuição dos pesos realizada pelo gestor máximo em comparação ao realizado pelos demais gestores, também é possível verificar maior dispersão nos pesos atribuídos dentro do conjunto de gestores subordinados ao gestor máximo, visto que o coeficiente de variação superior observado nesse grupo denota maior heterogeneidade dos pesos atribuídos em comparaçáo ao observado no processo realizado apenas pelo gestor máximo.

Ao realizar essa comparação ao detalhe das perspectivas do Public Value Scorecard, é possível notar por meio da Tabela 1 que a média dos pesos atribuídos pelos demais gestores é superior ao atribuído pelo 
Tabela 1. Média, Desvio Padráo e Coeficiente de Variaçáo dos Pesos Atribuídos aos Indicadores pelo Gestor Máximo e Principais Gestores com Base no Modelo Public Value Scorecard, por Perspectiva

\begin{tabular}{|c|c|c|c|c|c|}
\hline \multirow{2}{*}{ Nível Hierárquico } & \multirow{2}{*}{ Técnica } & \multirow{2}{*}{$\begin{array}{l}\text { Public Value } \\
\text { Scorecard }\end{array}$} & \multicolumn{3}{|c|}{ Perspectivas do Public Value Scorecard } \\
\hline & & & Missão Social & Legitimidade e Apoio & Capacidades Operacionais \\
\hline \multirow[t]{3}{*}{ (a) Gestor Máximo } & Média & 3,767 & 3,947 & 3,200 & 3,929 \\
\hline & Desvio Padrão & 0,649 & 0,229 & 0,789 & 0,730 \\
\hline & Cvar & 0,172 & 0,058 & 0,247 & 0,186 \\
\hline \multirow[t]{3}{*}{ (b) Demais Gestores $(\mathrm{c}+\mathrm{d}+\mathrm{e})$} & Média & 4,127 & 4,196 & 4,097 & 4,067 \\
\hline & Desvio Padrão & 0,973 & 0,884 & 1,104 & 0,928 \\
\hline & Cvar & 0,236 & 0,211 & 0,269 & 0,228 \\
\hline \multirow[t]{3}{*}{ (c) 2o Nível Hierárquico } & Média & 4,692 & 4,723 & 4,600 & 5,000 \\
\hline & Desvio Padrão & 0,459 & 0,437 & 0,548 & - \\
\hline & Cvar & 0,098 & 0,093 & 0,119 & - \\
\hline \multirow[t]{3}{*}{ (d) $3^{\circ}$ Nível Hierárquico } & Média & 3,821 & 3,704 & 3,783 & 3,982 \\
\hline & Desvio Padrão & 1,070 & 1,046 & 1,413 & 0,739 \\
\hline & Cvar & 0,280 & 0,283 & 0,374 & 0,186 \\
\hline \multirow[t]{3}{*}{ (e) 4o Nível Hierárquico $(\mathrm{f}+\mathrm{g})$} & Média & 4,210 & 4,343 & 4,157 & 4,090 \\
\hline & Desvio Padrão & 0,928 & 0,768 & 1,014 & 1,006 \\
\hline & Cvar & 0,220 & 0,177 & 0,244 & 0,246 \\
\hline \multirow{3}{*}{$\begin{array}{l}\text { (f) } 4^{\circ} \text { Nível Hierárquico: } \\
\text { Unidades de Suporte }\end{array}$} & Média & 4,177 & 3,722 & 4,214 & 4,261 \\
\hline & Desvio Padrão & 0,787 & 0,574 & 0,736 & 0,864 \\
\hline & Cvar & 0,188 & 0,154 & 0,175 & 0,203 \\
\hline \multirow{3}{*}{$\begin{array}{l}\text { (g) 4o Nível Hierárquico: } \\
\text { Unidades Finalísticas }\end{array}$} & Média & 4,219 & 4,389 & 4,136 & 3,987 \\
\hline & Desvio Padrão & 0,966 & 0,763 & 1,102 & 1,081 \\
\hline & Cvar & 0,229 & 0,174 & 0,266 & 0,271 \\
\hline
\end{tabular}

Nota. Fonte: Dados da pesquisa

gestor máximo nas três perspectivas. Ademais, é possível observar que a maior discrepância em relação às médias ocorreu para a perspectiva «Legitimidade e Apoio» (4,097 pelos demais gestores contra 3,2 pelo gestor máximo). Entretanto, apesar de essa mesma perspectiva apresentar a maior heterogeneidade para os pesos atribuídos pelos gestores $(0,269)$, é possível observar que o coeficiente de variação é o mais próximo do ocorrido com relação aos pesos atribuídos pelo gestor máximo ao comparar os resultados obtidos nas três perspectivas $(0,247)$. Nesse ponto, verifica-se que ocorre maior dispersão nos pesos atribuídos pelos demais gestores em comparação ao atribuído pelo ges- 
tor máximo na perspectiva «Missão Social» $(0,211 \mathrm{de}$ demais gestores contra 0,058 do gestor máximo).

Com a análise dos indicadores de forma individual, é possível conhecer quais os itens que apresentaram maior contribuição para as variaçóes retrocitadas. Com relação à diferença de médias ocorrida na perspectiva "Legitimidade e Apoio», a aplicação das técnicas de estatística descritiva para os 43 indicadores de forma semelhante ao apresentado na Tabela 1 indicam que dois indicadores teriam maior participação na diferença de pesos atribuídos: (i) indicador 24: percentual de equipamentos hospitalares recebidos com base em projetos elaborados para captaçáo de equipamentos (peso 2 de acordo com o gestor principal e média 3,313 de acordo com os demais gestores); (ii) indicador 28: alcançar certificado de acreditação hospitalar nível 3 (peso 3 de acordo com o gestor principal e média 4,214 de acordo com os demais gestores).

Já com relação à maior dispersão observada para a perspectiva "Missão Social», notou-se a importante participação de dois indicadores nessa ocorrência: (i) indicador 5: implantação da unidade básica ligada ao hospital por meio de convênio com o gestor municipal (coeficiente de variação 0,495 para os demais gestores); (ii) indicador 18: percentual de satisfação do aluno quanto ao atendimento humanizado (coeficiente de variação de 0,315 para os demais gestores).

\subsection{Comparaçáo entre a percepçáo do gestor máximo e dos demais gestores por nível hierárquico}

Após a realização de uma análise global a respeito das discrepâncias de médias e de dispersóes entre os pesos atribuídos pelo gestor máximo e os demais gestores subordinados, buscou-se realizar uma análise de forma estratificada, considerando o nível hierárquico dos gestores, para verificação de possíveis acentuaçóes nas variaçóes como consequência de um maior distanciamento no organograma institucional.

Tomando como base as informaçôes presentes na Tabela 1, é possível observar que há diferenças na atribuição de pesos realizada pelos gestores em cada um dos níveis hierárquicos analisados na instituição, sendo que, em média, os três níveis hierárquicos subordinados atribuem maior peso para os indicadores do que o ocorrido com o gestor máximo, o que demonstra a importância dos indicadores elaborados e cascateados pelo ponto de vista desses indivíduos. Destaca-se, nesse sentido, que as assessorias, áreas diretamente subordinadas à direção geral e que, no organograma da instituição, localizam-se no segundo nível hierárquico, são as que apresentam maior diferença para a média de pesos observada junto ao gestor principal (média de 4,692 das assessorias contra 3,767 do gestor máximo), estando em seguida o nível de unidades gerenciais $(4,210)$ e, de forma mais aderente, os diretores de área $(3,821)$.

Já com relação à dispersão, observa-se por meio da Tabela 1 que há maior heterogeneidade na atribuição de pesos realizada pelos diretores de área, localizados no terceiro nível hierárquico analisado $(0,280)$, tanto em comparação ao ocorrido na análise empreendida sobre os pesos atribuídos pelo gestor principal quanto para as demais áreas, como o nível de unidades gerenciais $(0,220)$, que também um conjunto com maior heterogeneidade quando comparado ao ocorrido com o gestor máximo $(0,172)$. As assessorias também apresentaram uma dispersão diferente do ocorrido com o gestor máximo, entretanto nota-se que, ao contrário do ocorrido com os demais níveis hierárquicos, o conjunto de pesos atribuídos pelos assessores apresenta um resultado mais homogêneo $(0,098)$. 
A análise de acordo com as perspectivas do Public Value Scorecard é capaz de trazer maiores informaçôes a respeito dos eventos supracitados. Com relação à diferença de médias entre o gestor principal e as assessorias, observa-se que tal discrepância ocorre de forma mais severa na perspectiva "Legitimidade e Apoio». Ao observar o apresentado na Tabela 1, nota-se uma média de 4,6 nessa perspectiva pelas assessorias, enquanto para essa mesma perspectiva o gestor máximo atribuiu pesos com resultado médio de 3,2. Nesse sentido, também é interessante observar que, para os três níveis hierárquicos localizados abaixo do gestor principal, a perspectiva "Legitimidade e Apoio» é a que apresenta a maior discrepância.

Com relação à dispersão na atribuição de pesos, ao verificar com base nas perspectivas do Public Value Scorecard, nota-se por meio da Tabela 1 que a maior heterogeneidade observada para o nível de diretorias de área se deve principalmente à perspectiva «Missão Social» (coeficiente de variação de 0,283 para as diretorias de área e 0,058 para o gestor principal), sendo essa perspectiva verificada como a que possui maior heterogeneidade em comparação ao verificado junto ao gestor principal para os três níveis hierárquicos subordinados. Quanto à maior homogeneidade verificada para o conjunto de pesos atribuídos pelas assessorias em comparação ao verificado junto ao gestor principal, verifica-se sob o prisma das perspectivas que o grupo «Legitimidade e Apoio» possui importante papel nessa ocorrência (coeficiente de variação de 0,119 para as assessorias e 0,247 para o gestor principal).

Ao verificar os indicadores específicos envolvidos nos eventos apontados, notou-se que o indicador 28 (alcançar certificado de acreditaçáo hospitalar nível 3) é o que apresentou maior grau de controvérsia ao comparar a importância atribuída pelo gestor máximo e

pelas assessorias (peso 3 atribuído pelo gestor principal e média 5 atribuída pelas assessorias). Quanto à maior dispersão verificada na perspectiva "Missão Social» para as diretorias de área em relação ao ocorrido junto ao gestor principal, a análise dos indicadores de forma isolada indica maiores variaçóes para dois indicadores (i) indicador 5: implantação da unidade básica ligada ao hospital por meio de convênio com o gestor municipal (coeficiente de variação 0,707 para as diretorias de área); (i) indicador 1: \% satisfação dos pacientes verificada por meio de pesquisa de satisfação (coeficiente de variação 0,339 para as diretorias de área).

Tomando em consideração a estrutura hierárquica da organização, é possível realizar inferências levando em conta o papel de determinadas unidades no funcionamento da organização, o que também pode influenciar nas diferenças na atribuiçãa de pesos. Nesse sentido, realizou-se uma análise aos mesmos moldes do ocorrido para os diferentes níveis hierárquicos e, por sua vez, estratificando as unidades gerenciais presentes no quarto nível hierárquico em dois agrupamentos: unidades finalísticas e unidades de suporte. Sob esse prisma, verifica-se de acordo com a Tabela 1 que a média atribuída pelas unidades finalísticas $(4,219)$ é superior à média atribuída pelas unidades de suporte $(4,177)$ e, com relação à dispersão, o coeficiente de variação calculado para cada agrupamento aponta maior heterogeneidade para os pesos atribuídos pelas unidades finalísticas $(0,229)$ em comparação às unidades de suporte $(0,188)$.

\section{Conclusóes}

A análise empreendida em um hospital universitário federal da regiáo Sul do Brasil, com o objetivo de verificar se ocorrem diferenças no processo de hierarquização de elementos para a avaliação de desempenho organizacional entre diferentes níveis hierárquicos, 
tomando como base o modelo Public Value Scorecard, demonstrou inicialmente a ocorrência de discrepâncias entre os pesos atribuídos pelo gestor principal da organização e os pesos atribuídos por gestores subordinados a indicadores cascateados a eles, tanto ao considerar as diferenças entre médias - o que demonstrou a atribuiçáo de maior peso aos indicadores pelos gestores subordinados - quanto ao verificar a dispersão entre os pesos atribuídos - o que demonstrou maior heterogeneidade nas áreas subordinadas do que no conjunto de pesos atribuídos pelo gestor principal.

Dessa forma, os resultados verificados empiricamente podem reforçar os pressupostos teóricos observados na literatura acadêmica a respeito do papel da atribuição de pesos a indicadores como um importante elemento para promoção do alinhamento estratégico de uma organização (Bergeron et al., 2004; Chenhall, 2005; Bush et al., 2009), especialmente quando se busca promover o alinhamento assumindo a percepção do gestor máximo da organização, considerando esse o elemento mediador dos possíveis conflitos de interesse que podem permear o processo de definiçáo de prioridades em um rol de indicadores e metas de desempenho (Kaplan \& Norton, 2006). Vale ressaltar que as conclusões baseadas no estudo empírico são reforçadas ao considerar o enquadrado do caso escolhido como um caso decisivo, já que os pressupostos foram confirmados junto a gestores com tempo no cargo atual e na organização consideravelmente elevados.

Também convém ressaltar que determinadas perspectivas do modelo Public Value Scorecard podem apresentar maiores discrepâncias no processo de definição de prioridades em indicadores de desempenho elaborados com base nesse artefato, informação esta que pode contribuir no processo de implantação desse modelo em entidades semelhantes à estudada. Os resultados da pesquisa indicaram, no estudo de caso empreendido, que a perspectiva «Legitimidade e Apoio» se mostrou mais propensa a diferenças na atribuição de pesos para indicadores entre o gestor principal e demais gestores, tomando como base a diferença de médias entre os conjuntos de pesos nos diferentes grupos de gestores.

Já em relação à dispersão, verificou-se que a perspectiva «Missão Social» apresentou maior heterogeneidade na comparação realizada entre a atribuição de pesos realizada pelo gestor principal e pelos demais gestores, tanto de forma geral quanto nos estratos analisados. Tal inferência é particularmente importante para o processo de modelagem e implantaçáo do Public Value Scorecard em entidades assemelhadas, visto que essa perspectiva concentra os elementos-chave para verificação do sucesso da estratégia organizacional de entidades sem finalidades lucrativas, fazendo-se salutar a promoção de um adequado alinhamento estratégico nesse item em especial.

Quanto à análise estratificada por nível hierárquico, buscando o atendimento do segundo objetivo definido para a investigação, as evidências apresentadas não demonstram a existência de aumento nas diferenças nos pesos atribuídos aos indicadores com relação ao aumento do distanciamento na hierarquia da empresa. Conforme apresentado na análise de dados, a inferência indicou que o nível hierárquico mais próximo do gestor principal - as assessorias - apresentou maior diferença de médias em comparação ao verificado com base nas comparaçóes de resultados entre gestor máximo e os demais níveis hierárquicos mais distanciados hierarquicamente; e tomando com base o coeficiente de variação, também se indica que a área mais distante hierarquicamente do gestor principal não apresenta maior dispersão do que as demais áreas analisadas, já que as diretorias de área - hierarquicamente superiores às unidades gerenciais - demonstraram 
maior diferença na comparação entre os coeficientes de variação calculados com base nos pesos atribuídos aos indicadores, bem como maior heterogeneidade.

Como as análises empreendidas foram realizadas com base em um estudo de caso único, realizado em um hospital universitário federal e com base no Public Value Scorecard, determinados resultados podem estar relacionados em maior grau à realidade estudada. Entretanto, além da possibilidade de agregar informaçóes empíricas ao estado da arte sobre pesquisas em contabilidade e controle gerencial em organizaçóes públicas e hospitalares, bem como sobre a abordagem do modelo Public Value Scorecard e sobre a atribuição de pesos a indicadores de desempenho, informaçôes obtidas por meio dessa investigação podem fornecer subsídios práticos quanto ao processo de modelagem, implantação e atualização de artefatos estratégicos de avaliação de desempenho em entidades semelhantes, em especial para instituiçôes hospitalares, com enfoque ao tema de hierarquização de elementos para a avaliação e distribuição de recompensas. Com isso, há de se considerar que os diversos elementos discutidos nesse estudo podem estar presentes nessas organizaçóes, o que pode contribuir para uma análise crítico-construtiva de um problema prático que se remeta ao tema abordado. Sugere-se, nesse sentido, a realização de estudos semelhantes em entidades análogas que já utilizam algum sistema estratégico de avaliação de desempenho, bem como em entidades com características diferentes, como organizaçóes com finalidades lucrativas.

\section{Referências}

Abernethy, M. A., W. F. Chua, J. Grafton \& H. Mahama (2007). Conceptual accounting and control in health care: behavioural, organisational, sociological and critical perspectives. In C. S. Chapman, A. G. Hopwood
\& M. D. Shields (Orgs.), Handbook of Management Accounting Research (Vol. 2, pp. 805-829), Amsterdã: Elsevier.

ANS - Agência Nacional de Saúde Suplementar (2014). Relatório de Qualificação das Operadoras 2014, Ano Base 2013. Brasília: ANS.

Assiri, A., M. Zairi \& R. Eid (2006). How to profit from the balanced scorecard: An implementation roadmap. Industrial Management \& Data Systems, 107(7), 937. https://doi.org/10.1108/02635570610688869

Avison, D., J. Jones, P. Powell \& D. Wilson, D. (2004). Using and validating the strategic alignment model. Journal of Strategic Information Systems, 13(3), 223246. https://doi.org/10.1016/j.jsis.2004.08.002

Baker, G., R. Gibbons \& K. J. Murphy (1994). Subjective performance measures in optimal incentive contracts. The Quartely Journal of Economics, 109(4), 1125-1156. https://doi.org/10.2307/2118358

Banker, R. D., G. Potter \& D. Srinivasan (2000). An empirical investigation of an incentive plan that includes nonfinancial performance measures. The Accounting Review, 79(1), 1-23. https://doi.org/10.2308/accr.2004.79.1.1

Bart, C. K. \& J. C. Tabone (1998). Mission statement rationales and organizational alignment in the not-for-profit health care sector. Health Care Management Review, 23(4), 54-69. https://doi.org/10.1097/00004010199810000-00005

Bergeron, F., L. Raymond \& S. Rivard (2004). Ideal patterns of strategic alignment and business performance. Information \& Management, 41(8), 1003-1020. https://doi.org/10.1016/j.im.2003.10.004

Bortoluzzi, S. C., S. R. Ensslin, L. Ensslin \& E. F. R. Vicente (2010). Práticas de avaliaçáo de desempenho organizacional em pequenas e médias empresas: investigaçáo em uma empresa de porte médio do ramo moveleiro. Revista Produção Online, 10(3), 551-576. https://doi.org/10.14488/1676-1901.v10i3.244 
Boulianne, E. (2012). Weight or not weight the Balanced Scorecard's dimensions for performance evaluation. In 35 European Accounting Association Annual Congress, Ljubljana, Eslovênia.

Bryman, A. (2012). Social research methods (4a ed.). New York: Oxford University Press.

Bush, M., A. L. Lederer, X. Li, J. Palmisano \& S. Rao (2009). The alignment of information systems with organizational objectives and strategies in health care. International Journal of Medical Informatics, 78(7), 446456. https://doi.org/10.1016/j.ijmedinf.2009.02.004

Chenhall, R. H. (2005). Integrative strategic performance measurement systems, strategic alignment of manufacturing, learning and strategic outcomes: an exploratory study. Accounting, Organizations and Society, 30(5), 395-422. https://doi.org/10.1016/j.aos.2004.08.001

Chenhall, R. H. \& K. Langfield-Smith (1998). Adoptions and benefits of management accounting practices: an Australian study. Management Accounting Research, 9(1), 1-19.

Chenhall, R. H. \& K. Langfield-Smith (2003). Performance measurement and reward systems, trust and strategic change. Journal of Management Accounting Research, 15(1), 117-143. https://doi.org/10.2308/ jmar.2003.15.1.117

Datar, S., S. C. Kulp \& R. A. Lambert (2001). Balancing performance measures. Journal of Accounting Research, 39(1), 75-92. https://doi.org/10.1111/1475-679X.00004

Debus, I. (2012). Análise dos Contratos de Gestão Celebrados com as Agências Reguladoras quanto à Regularidade, Efetividade e Contribuição para a Gestão Regulatória e Fiscalizatória. Comitê Gestor do Programa de Fortalecimento da Capacidade Institucional para a Gestão Regulatória. Brasília: Presidência da República.

Debusk, G. K., R. M. Brown \& L. N. Killough (2003) Components and relative weights in utilization of dashboard measurement systems like the Balanced Scorecard. The British Accounting Review, 35(3), 215-231. https:// doi.org/10.1016/S0890-8389(03)00026-X
Dong, X., Q. Liu \& D. Yin (2008). Business performance, business strategy, and information system strategic alignment: an empirical study on chinese firms. Tsinghua Science and Technology, 13(3), 348-354. https:// doi.org/10.1016/S1007-0214(08)70056-7

Elzinga, T., B. Albronda \& F. Kluijtmans (2009). Behavioral factors influencing performance management systems' use. International Journal of Productivity and Performance Management, 58(6), 508-522. https:// doi.org/10.1108/17410400910977064

Evans, J. H., Y. Hwang \& N. J. Nagarajan (2001). Management control and hospital cost reduction: additional evidence. Journal of Accounting and Public Policy, 20 (1), 73-88. https://doi.org/10.1016/S02784254(00)00024-7

Franco-Santos, M. \& M. Bourne (2005). An examination of the literature relating to issues affecting how companies manage through measures. Production Planning and Control, 16(21), 114-124. https://doi.org/10.108 o/09537280512331333020

Franco-Santos, M., L. Lucianetti \& M. Bourne (2012). Contemporary performance measurement systems: a review of their consequences and a framework for research. Management Accounting Research, 23(2), 79-119. https://doi.org/10.1016/j.mar.2012.04.001

Galas, E. S. \& V. M. R. Ponte (2006). O Balanced Scorecard e o alinhamento estratégico da tecnologia da informação: um estudo de casos múltiplos. Revista de Contabilidade \& Finanças, 17(40), 37-51.

GESPÚBLICA - Programa Nacional de Gestão Pública e Desburocratização (2009). Guia Referencial para Medição de Desempenho e Manual para Construção de Indicadores. Brasília: Ministério do Planejamento.

Herath, H. S., W. G. Bremser \& J. G. Birnberg (2010). Facilitating a team culture: a collaborative balanced scorecard as an open reporting system. Advances in Management Accounting, 18, 149-713. https://doi. org/10.1108/S1474-7871(2010)0000018009 
Ittner, C. D. \& D. F. Larcker (2003). Coming up short on nonfinancial performance measurement. Harvard Business Review, 5380, 1-11.

Ittner, C. D., D. F. Larcker \& M. W. Meyer (2003). Subjectivity and the weighting of performance measures: evidence from a Balanced Scorecard. The Accounting Review, 78(3), 725-758. https://doi.org/10.2308/ accr.2003.78.3.725

Joshi, M., R. Kathuria \& S. J. Porth (2003). Alignment of strategic priorities and performance: an integration of operations and strategic management perspectives. Journal of Operations Management, 21(3), 353-369. https://doi.org/10.1016/S0272-6963(03)00003-2

Kaplan, R. S. (2001). Strategic performance measurement and management in nonprofit organizations. Nonprofit Management \& Leadership, 11(3), 353-370. https:// doi.org/10.1002/nml.11308

Kaplan, R. S. (2009). Conceptual foundations of the balanced scorecard. In C. S. Chapman, A. G. Hopwood \& M. D. Shields (Orgs.), Handbook of Management Accounting Research (vol. 3, pp. 1253-1269). Ámsterdam: Elsevier. https://doi.org/10.1016/s1751-3243(07)03003-9

Kaplan, R. S. \& D. P. Norton (1996). Using the balanced scorecard as a strategic management system. Harvard Business Review. Boston, 75-85.

Kaplan, R. S. \& D. P. Norton (2001). The strategy focused organization. Boston: Harvard Business School Press.

Kaplan, R. S. \& D. P. Norton (2006). Alignment: using the balanced scorecard to create corporate synergies. Boston: Harvard Business School Press.

Kelly, K. (2010). Accuracy of relative weights on multiple leading performance measures: effects on managerial performance and knowledge. Contemporary Accounting Research, 27(2), 577-608. https://doi.org/10.1111/ j.1911-3846.2010.01017.x

Lipe, M. G. \& S. E. Salterio (2000). The Balanced Scorecard: judgemental effects of common and unique performance measures. The Accounting Review, 75(3), 283-298. https://doi.org/10.2308/accr.2000.75.3.283

Malina, M. A. \& F. H. Selto (2001). Communicating and controlling strategy: an empirical study of the effectiveness of the balanced scorecard. Journal of Management Accounting Research, 13(1), 47-90. https://doi.org/10.2308/jmar.2001.13.1.47

Moore, M. H. (2003). The Public Value Scorecard: a rejoinder and an alternative to «strategic performance measurement and management in non-profit organizations» by Robert Kaplan. Hauser Center for Nonprofit Organizations. Cambridge, Inglaterra. https://doi.org/10.2139/ssrn.402880

Powell, T. C. (1992). Organizational alignment as competitive advantage. Strategic Management Journal, 13(2), 119-134. https://doi.org/10.1002/smj.4250130204

Smith, M. J. (2002). Gaming nonfinancial performance measures. Journal of Management Accounting Research, 14(1), 119-133. https://doi.org/10.2308/ jmar.2002.14.1.119

Veen-Dirks, P. V. (2010). Different uses of performance measures: the evaluation versus reward of production managers. Accounting, Organizations and Society, 35(2), 141-164. https://doi.org/10.1016/j.aos.2009.02.002

Waal, A. A. (2003). Behavioral factors important for the successful implementation and use of performance management systems. Management Decision, 41(8), 688-697. https://doi. org/10.1108/00251740310496206

Yin, R. K. (2001). Estudo de caso: planejamento e métodos (2a ed.). Porto Alegre: Bookman.

Zhang, S. \& Wang L. (2010). A public value approach to service management in public hospitals: an alternative to the balanced scorecard. In 4 International Conference on Management and Service Science, Wuhan, China. https://doi.org/10.1109/icmss.2010.5577188 


\section{Apêndice A - Proposta do PVS para a Direção Geral da instituição}

\begin{tabular}{|c|c|c|}
\hline Perspectiva & Objetivo & Indicador \\
\hline \multirow[t]{19}{*}{$\begin{array}{l}\text { Missão } \\
\text { social }\end{array}$} & \multirow[t]{3}{*}{ Atingir a satisfação pelo ponto de vista dos clientes } & $\begin{array}{l}\text { Satisfação dos pacientes por meio de pesquisa de satis- } \\
\text { fação }\end{array}$ \\
\hline & & Satisfação dos estudantes \\
\hline & & Satisfação dos professores da área de Ciências da Saúde \\
\hline & $\begin{array}{l}\text { Incrementar o nível de produção de conhecimento por } \\
\text { meio de pesquisas e publicaçóes }\end{array}$ & Implantação do núcleo de apoio ao pesquisador \\
\hline & $\begin{array}{l}\text { Firmar convênio para criar uma unidade básica para } \\
\text { compor o complexo hospitalar para atender todos os } \\
\text { níveis }\end{array}$ & $\begin{array}{l}\text { Implantaçáo da unidade básica ligada ao hospital por } \\
\text { meio de convênio com o gestor municipal }\end{array}$ \\
\hline & $\begin{array}{l}\text { Contribuir para situar os cursos da área de saúde entre os } \\
\text { mais bem avaliados entre o Ministério da Educação }\end{array}$ & $\begin{array}{l}\text { Resultado do Exame Nacional de Desempenho dos } \\
\text { Estudantes }\end{array}$ \\
\hline & \multirow[t]{3}{*}{ Formar cidadãos por meio do processo educacional } & $\begin{array}{l}\text { Alinhamento do currículo e atividades extracurriculares } \\
\text { com as diretrizes do Ministério da Educação e Ministério } \\
\text { da Educaçáo para formação do profissional cidadão }\end{array}$ \\
\hline & & $\begin{array}{l}\text { Adesão ao Código de Conduta do hospital pelos alunos } \\
\text { de graduaçáo e pós-graduaçáo }\end{array}$ \\
\hline & & $\begin{array}{l}\text { Adesão ao Código de Conduta do hospital pelos profis- } \\
\text { sionais do hospital }\end{array}$ \\
\hline & Promover a formação multidisciplinar & $\begin{array}{l}\text { \% de equipes multidisciplinares implantadas com acordo } \\
\text { com deliberaçóes do Ministério da Saúde }\end{array}$ \\
\hline & \multirow[t]{7}{*}{ Acolher e assistir o paciente com resolutividade } & $\begin{array}{l}\% \text { de retornos dos pacientes ao pronto-atendimento do } \\
\text { hospital }\end{array}$ \\
\hline & & $\%$ de retornos dos pacientes dentro do prazo definido \\
\hline & & Taxa de ocupação hospitalar \\
\hline & & $\%$ de exames complementares por paciente \\
\hline & & Taxa de permanência \\
\hline & & Taxa de infecção hospitalar \\
\hline & & Taxa de mortalidade \\
\hline & \multirow[t]{2}{*}{ Promover o atendimento humanizado } & Satisfação do aluno quanto ao atendimento humanizado \\
\hline & & $\begin{array}{l}\text { Satisfação do paciente quanto ao atendimento humani- } \\
\text { zado }\end{array}$ \\
\hline
\end{tabular}




\begin{tabular}{|c|c|c|}
\hline Perspectiva & Objetivo & Indicador \\
\hline \multirow[t]{11}{*}{$\begin{array}{l}\text { Legitimidade e } \\
\text { apoio }\end{array}$} & $\begin{array}{l}\text { Manter a existência de um quadro de voluntários sociais } \\
\text { e profissionais na entidade }\end{array}$ & Número de voluntários registrados \\
\hline & $\begin{array}{l}\text { Manter o conceito de instituição segura, confiável e de } \\
\text { alta qualidade junto a mídia }\end{array}$ & Número de matérias positivas na mídia \\
\hline & $\begin{array}{l}\text { Reverter a imagem de instituição voltada apenas para } \\
\text { atender a população carente }\end{array}$ & $\begin{array}{l}\text { Quantidade de fontes internas para divulgação das açóes } \\
\text { do hospital voltada à divulgação de pesquisas }\end{array}$ \\
\hline & $\begin{array}{l}\text { Aumentar a capacidade de captação, processamento e } \\
\text { distribuiçấo de materiais biológicos }\end{array}$ & $\begin{array}{l}\text { Recredenciamento do banco de tecidos musculoesque- } \\
\text { lético }\end{array}$ \\
\hline & Aumentar a captação de equipamentos hospitalares & $\begin{array}{l}\% \text { de equipamentos recebidos com base em projetos } \\
\text { elaborados }\end{array}$ \\
\hline & $\begin{array}{l}\text { Melhorar os processos de trabalho de modo a cumprir as } \\
\text { exigências dos órgãos reguladores }\end{array}$ & $\begin{array}{l}\text { Número de autos de infração e recomendaçôes de } \\
\text { auditoria }\end{array}$ \\
\hline & $\begin{array}{l}\text { Criar canais de comunicação com sindicatos e conselhos } \\
\text { regionais de modo a estabelecer o perfil de atuaçáo mais } \\
\text { adequado em relaçáo ao hospital }\end{array}$ & $\begin{array}{l}\text { Número de crises e ocorrências com os órgãos represen- } \\
\text { tativos da sociedade civil }\end{array}$ \\
\hline & Aumentar a captação de recursos financeiros & Receita obtida \\
\hline & $\begin{array}{l}\text { Oferecer assistência acreditada em nível } 3 \text { da Organi- } \\
\text { zaçáo Nacional de Acreditaçáo aos clientes em } 4 \text { anos }\end{array}$ & $\begin{array}{l}\text { Nível de acreditação pela Organização Nacional de } \\
\text { Acreditação }\end{array}$ \\
\hline & Aumentar o reconhecimento da marca & $\begin{array}{l}\% \text { reconhecimento pela comunidade interna e externa } \\
\text { verificada por meio de pesquisa }\end{array}$ \\
\hline & $\begin{array}{l}\text { Determinar os níveis contratuais com o Sistema Único } \\
\text { de Saúde }\end{array}$ & Pactuação dos níveis contratuais pelas partes envolvidas \\
\hline \multirow[t]{7}{*}{$\begin{array}{l}\text { Capacidades } \\
\text { operacionais }\end{array}$} & $\begin{array}{l}\text { Ampliar as parceiras com instituições e manter as } \\
\text { parcerias existentes por manutençáo de comunicação e } \\
\text { contato social }\end{array}$ & Número de instituiçóes parceiras \\
\hline & $\begin{array}{l}\text { Pactuar com Setor de Ciências da Saúde e departamentos } \\
\text { de ensino todas as atividades assistenciais desenvolvidas } \\
\text { no complexo hospitalar }\end{array}$ & $\begin{array}{l}\% \text { de pactos fechados com o setor e departamentos de } \\
\text { ensino e assistência }\end{array}$ \\
\hline & $\begin{array}{l}\text { Elaborar e implantar a política interna de gestấo de } \\
\text { pessoas }\end{array}$ & $\begin{array}{l}\text { \% de implantação da Política Interna de Gestão de } \\
\text { Pessoas }\end{array}$ \\
\hline & $\begin{array}{l}\text { Adequar a produtividade conforme o pactuado com o } \\
\text { Sistema Único de Saúde e as necessidades de ensino }\end{array}$ & $\%$ de procedimentos pactuados e devidamente faturados \\
\hline & Alcançar a sustentabilidade financeira & Índice de sustentabilidade financeira \\
\hline & \multirow[t]{2}{*}{ Garantir a inovação, a atualização e a excelência } & Número de parcerias com instituições de pesquisa \\
\hline & & $\begin{array}{l}\text { Número de pesquisas conjuntas com instituiçóes de } \\
\text { pesquisa construídas por meio do núcleo de apoio ao } \\
\text { pesquisador, grupos de pesquisa e programas de pós- } \\
\text { graduaçáo }\end{array}$ \\
\hline
\end{tabular}




\begin{tabular}{|c|c|c|}
\hline Perspectiva & Objetivo & Indicador \\
\hline & Implantar um centro de telemedicina, em 4 anos & \% implantação do centro de telemedicina \\
\hline & Implementar a Política Nacional de Humanização & \% implantação da Política Nacional de Humanização \\
\hline & Implantar as Unidades Gerenciais & $\%$ de unidades gerenciais implantadas \\
\hline & Implantar o Plano Diretor de Tecnologia de Informação & $\begin{array}{l}\text { \% implantação do Plano Diretor de Tecnologia de } \\
\text { Informaçáo }\end{array}$ \\
\hline & \multirow{3}{*}{$\begin{array}{l}\text { Proporcionar estrutura adequada para ensino, pesquisa, } \\
\text { extensão concomitantemente com a assistência }\end{array}$} & \% de obras de adequação completadas \\
\hline & & \% de solicitações de manutenção completadas \\
\hline & & \% satisfação dos clientes internos sobre a infraestrutura \\
\hline & $\begin{array}{l}\text { Pactuar com os envolvidos simultaneamente com o } \\
\text { ensino e a assistência }\end{array}$ & $\begin{array}{l}\% \text { de pactos fechados com o setor e departamentos de } \\
\text { ensino e assistência }\end{array}$ \\
\hline
\end{tabular}

Fecha de recepción: 01 de marzo de 2016

Fecha de aceptación: 25 de junio de 2016

Correspondencia: henrique.portulhak@ufpr.br

marciabortolocci@gmail.com 